\title{
Palaeobiology of orthothecide hyoliths from the Cambrian Manto Formation of Hebei Province, North China
}

\author{
Haijing Sun, John M. Malinky, Maoyan Zhu, and Diying Huang \\ Acta Palaeontologica Polonica 63 (1), 2018: 87-101 doi:https://doi.org/10.4202/app.00413.2017
}

Newly discovered specimens of the orthothecide hyoliths in Hebei Province of North China reveal new data on diversity, skeletal microstructure and palaeoecology of the order Orthothecida. Decoritheca cyrene possesses a well-defined skeletal structure consisting of rows of tubercles in the shell wall, which correspond to dimples on the internal surface of the conch. We describe a new species Cupitheca convexa sp. nov. characterised by a planar and interior convex operculum with a pair of bilobate cardinal processes, which differs from the more widespread $C$. holocyclata in opercular morphology and overall ornamentation of the conch, highting the significance of operculum in the classification of hyoliths. First discovery of the presumed unusual protoconch of $C$. convexa sp. nov. implies a possible lecithotrophic development to adapt to nutrient-fluctuant environments. Pitting structure on the operculum and shell as well as lamellar- fibrillar structure on the internal mould of $C$. convexa sp. nov. are observed herein.

Key words: Hyolitha, Orthothecida, ontogeny, larval conch, skeletal microstructure, Cambrian, China.

Haijing Sun [hjsun@nigpas.ac.cn] (corresponding author) and Diying Huang [매huang@nigpas.ac.cn ] (corresponding author), State Key Laboratory of Palaeobiology and Stratigraphy, Nanjing Institute of Geology and Palaeontology, Chinese Academy of Sciences, Nanjing 210008, China. John M. Malinky [jmalinky@ sbcglobal.net ], Department of Physical Science, San Diego City College, 1313 Park Boulevard, San Diego, California, 92101, USA. Maoyan Zhu [myzhu@nigpas.ac.cn], State Key Laboratory of Palaeobiology and Stratigraphy, Nanjing Institute of Geology and Palaeontology, Chinese Academy of Sciences, Nanjing 210008, China, and College of Earth Sciences, University of Chinese Academy of Sciences, Beijing 100049, China.

This is an open-access article distributed under the terms of the Creative Commons Attribution License (for details please see creativecommons.org), which permits unrestricted use, 
distribution, and reproduction in any medium, provided the original author and source are credited.

Fafil Full text $(1,738.3 \mathrm{kB})$ ।

Far Supplementary file $(1,755.0 \mathrm{kB})$ 